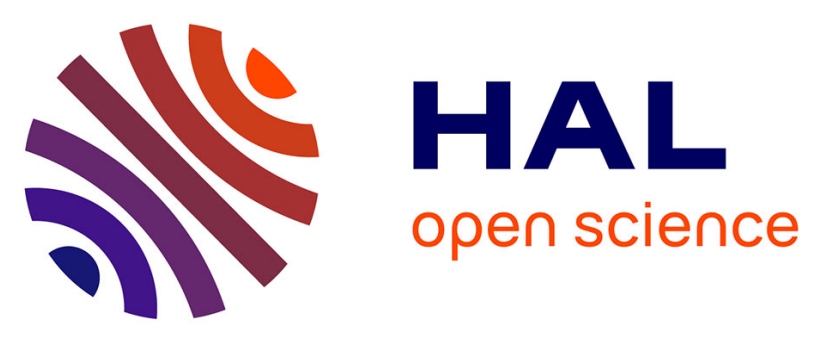

\title{
Silicon Isotope Analyses of Soil and Plant Reference Materials: An Inter-Comparison of Seven Laboratories
}

Camille Delvigne, Abel Guihou, Jan A Schuessler, Paul Savage, Franck

Poitrasson, Sebastian Fischer, Jade E Hatton, Katharine R Hendry, Germain Bayon, Emmanuel Ponzevera, et al.

\section{To cite this version:}

Camille Delvigne, Abel Guihou, Jan A Schuessler, Paul Savage, Franck Poitrasson, et al.. Silicon Isotope Analyses of Soil and Plant Reference Materials: An Inter-Comparison of Seven Laboratories. Geostandards and Geoanalytical Research, 2021, 45 (3), pp.525-538. 10.1111/ggr.12378 . hal03259365

\section{HAL Id: hal-03259365 https://hal.science/hal-03259365}

Submitted on 31 Aug 2021

HAL is a multi-disciplinary open access archive for the deposit and dissemination of scientific research documents, whether they are published or not. The documents may come from teaching and research institutions in France or abroad, or from public or private research centers.
L'archive ouverte pluridisciplinaire HAL, est destinée au dépôt et à la diffusion de documents scientifiques de niveau recherche, publiés ou non, émanant des établissements d'enseignement et de recherche français ou étrangers, des laboratoires publics ou privés. 
1 Silicon isotope analyses of soil and plant reference materials: an inter-comparison of seven

2 laboratories

3

4 Camille Delvigne $^{1,2,{ }^{*}}$, Abel Guihou ${ }^{1}$, Jan A. Schuessler ${ }^{3,4}$, Paul Savage ${ }^{5}$, Franck Poitrasson ${ }^{6}$,

5 Sebastian Fischer ${ }^{5}$, Jade E. Hatton ${ }^{7}$, Katharine R. Hendry ${ }^{7}$, Germain Bayon ${ }^{8}$, Emmanuel

6 Ponzevera $^{8}$, Bastian Georg ${ }^{9,10}$, Alisson Akerman ${ }^{6}$, Oleg S.Pokrovsky ${ }^{6,11}$, Jean-Dominique

7 Meunier $^{1}$, Pierre Deschamps ${ }^{1}$ and Isabelle Basile-Doelsch ${ }^{1}$

8

$9{ }^{1}$ Aix Marseille Univ., CNRS, IRD, INRAE, Coll. France, CEREGE, Europôle Méditerranée de

I'Arbois BP 8013545 Aix-en-Provence, cedex 4, France

2 Earth and Life Institute, Environmental sciences, Université catholique de Louvain,

L7.05.10, 1348, Louvain-la-Neuve, Belgium

${ }^{3}$ Thermo Fisher Scientific, Bremen, Germany

${ }^{4}$ GFZ German Research Centre for Geosciences, Potsdam, 14473, Germany

${ }^{5}$ School of Earth \& Environmental Sciences, University of St Andrews, Irvine Building, St

Andrews, KY16 9AL, UK

${ }^{6}$ Géoscience and Environment Toulouse (GET), UMR 5563 CNRS-University of Toulouse III-

IRD-CNES, 14 Avenue Edouard Belin, 31400 Toulouse, France

${ }^{7}$ School of Earth Sciences, University of Bristol, Wills Memorial Building, Queens Road,

Bristol, UK

${ }^{8}$ IFREMER, Marine Geosciences Unit, Brest, France 
${ }^{10}$ Agilent Technologies Canada, 6705 Millcreek Dr Mississauga, ON, L5N 5M4, Canada

${ }^{11}$ BIO-GEO-CLIM Laboratory, Tomsk State University, Lenina av., 36, Tomsk, Russia

*Corresponding author. Email : camille.delvigne@uclouvain.be

\section{Keywords}

silicon isotopes, reference materials, soil, plant, inter-comparison of measurements

\section{Mots clés}

Isotopes du silicium, matériaux de référence, sol, plante, intercomparaison de mesures

\section{Main message}

This inter-laboratory comparison exercise establishes the $\delta^{30} \mathrm{Si}$ and $\delta^{29} \mathrm{Si}$ values for four new soil reference materials and one plant reference material, for future use as secondary $\mathrm{Si}$ isotope reference materials. 


\section{Abstract}

The use of silicon ( $\mathrm{Si}$ ) isotopes has led to major advances in our understanding of the $\mathrm{Si}$ cycling in modern and past environments. This inter-laboratory comparison exercise provides the community with the first set of soil and plant reference materials with an analytically challenging matrix containing organic material, known to induce isotopic bias, for use as secondary reference materials in Si isotope analysis. Seven laboratories analysed four soil reference materials (GBW-07401, GBW-07404, GBW-07407, TILL-1) and one plant reference material (ERM-CD281). Participating laboratories employed a range of chemical preparation methods and analytical setups but all analyses were performed by MC-ICP-MS. Irrespective of the chemical preparation method or analytical conditions, the results show excellent agreement among laboratories within their respective external reproducibilities (2SD). Data were combined together to calculate $\delta^{29} \mathrm{Si}$ and $\delta^{30} \mathrm{Si}$ average values (relative to NBS 28) and their uncertainties ( $U$, expanded uncertainty; $k=2$, coverage factor). The $\delta^{30} \mathrm{Si}$ values are as follow: GBW-07401: $-0.27 \pm 0.06 \%$, GBW-07404: $-0.76 \pm 0.12 \%$, GBW-07407: $-1.82 \pm 0.17 \%$, TILL-1: $-0.16 \pm 0.06 \%$ and for ERM-CD281: $-0.28 \pm 0.11 \%$ o. Also, a compilation of published data provides an up-to-date average $\delta^{30}$ Si for BHVO-2 of $-0.28 \pm$ $0.08 \%$. 


\section{Introduction}

Silicon (Si), the second most abundant element in the Earth's crust, is a ubiquitous rockforming element and is considered as a key component of global biogeochemical cycles, due

to links with carbon cycling and other nutrient systems. Chemical weathering of silicate minerals controls atmospheric $\mathrm{CO}_{2}$ concentration and thus regulates climate over geological timescales (e.g., Berner et al., 1983). Silicate weathering also releases dissolved Si into the hydrosphere, and thereby ultimately controls the biological pump, because $\mathrm{Si}$ is an essential nutrient in marine and freshwater ecosystems (Nelson et al., 1995; Ragueneau et al., 2006). Although the oceanic Si cycle has been a key research focus for decades, the terrestrial Si cycle has since attracted more scientific attention after the important and complex role of vegetation was recognized (Conley 2002; Street-Perrott and Barker, 2008; Struyf and Conley, 2012). Processes occurring at the land-ocean interface and anthropogenic impacts are now actively studied using Si isotopic variations or "fingerprints" (Engström et al., 2010; Hughes et al., 2011, 2013; Mangalaa et al., 2017; Vandevenne et al., 2015).

Silicon has three stable isotopes: ${ }^{28} \mathrm{Si},{ }^{29} \mathrm{Si},{ }^{30} \mathrm{Si}$ with average relative isotope abundances of 92.23\%, 4.67\% and 3.10\%, respectively (Barnes et al., 1975; De Bièvre and Taylor, 1993).

Pioneering Si isotope investigations in natural systems showed the potential to provide better understanding of the biogeochemical cycle of $\mathrm{Si}$ in both modern and past environments (see Basile, 2006, for an early review). However, studies remained limited because of sometimes hazardous, but often delicate and time-consuming analytical methods. The advent of MC-ICP-MS instruments, combined with improved sample preparation techniques (e.g., Georg et al., 2006), have subsequently allowed Si isotope 
measurements to flourish and led to great advances in our understanding of the global Si cycle (see Poitrasson, 2017, for a more recent review).

For analyses, external matrix-matched reference materials are required to allow interlaboratory comparisons and to check for data quality for everyday analytical work particularly in systems where standard-sample bracketing is the traditional way to measure isotope ratios. To date, only three inter-laboratory comparisons have been published for Si isotopes (Reynolds et al., 2007; Hendry et al., 2011; Grasse et al., 2017). The first one focused on three pure $\mathrm{SiO}_{2}$ materials: Diatomite $\left(\delta^{30} \mathrm{Si}=+1.26 \pm 0.20 \%\right.$; from hereon, all reproducibilities will be given as 2 standard deviations unless otherwise stated), IRMM-018 $\left(\delta^{30} \mathrm{Si}=-1.65 \pm 0.22 \%\right.$ ) and Big Batch $\left(\delta^{30} \mathrm{Si}=-10.48 \pm 0.54 \%\right.$; Reynolds et al., 2007). The Diatomite reference material is still commonly included in analytical sequences to check for accuracy and precision; however, the last two are less frequently utilised because they are either highly fractionated (Big Batch) or potentially inhomogeneous (IRMM-018; Reynolds et al., 2007). For a better matching between $\delta^{30} \mathrm{Si}$ values of external standards and samples, and to account for any microstructural effect, a second inter-laboratory comparison reported on a Southern Ocean sponge material as an additional reference material for sponge spicule analyses (Hendry et al., 2011). A third inter-calibration study was motivated by the need to reliably compare the increasing number of $\mathrm{Si}$ isotope datasets of natural waters. External standards such as Diatomite (which is provided as a powdered, near-pure $\mathrm{SiO}_{2}$ sample) cannot account for any biases introduced by the specific sample preparation and matrices involved when dealing with natural waters. These samples may contain Si with concentration below $20 \mu \mathrm{moll} \mathrm{I}^{-1}$, which may require pre-concentrations steps or the processing of large amounts of sample, with potentially high salinity. With this in mind, Grasse et al. (2017) characterised two seawater samples (ALOHA 300, [Si] $=9 \mu \mathrm{mol} \mathrm{I}^{-1}, \delta^{30} \mathrm{Si}=$ 
$+1.66 \pm 0.13 \%$; ALOHA 1000, [Si] $=113 \mu \mathrm{mol} \mathrm{I}^{-1}, \delta^{30} \mathrm{Si}=+1.25 \pm 0.06 \%$; ). The analyses of these "ALOHA" standards is now recommended when laboratories are reporting on seawater Si isotope data. In addition to this collection of reference materials, there are more than a dozen silicate rock reference materials that have enough extant published data to be suitable as external standards for silicate rock analyses (e.g., Abraham et al., 2008; Hughes et al., 2011; Zambardi and Poitrasson, 2011; Savage et al., 2014). Among these reference materials, the Hawaiian basalt BHVO-2 (provided by the USGS) is the most commonly analysed. A valuable compilation of $\delta^{30} \mathrm{Si}$ values suggest that the reference value for BHVO-2 is $\delta^{30} \mathrm{Si}=-0.28 \pm 0.03 \%$ (Savage et al., 2014) and more data are added continuously (see the GeoReM database).

Among the possible matrix effects on Si isotope measurements, the presence of anions such as sulfate (Van den Boorn et al., 2009) or dissolved organic carbon (DOC) (Hughes et al., 2011) has been reported to produce mass bias changes during MC-ICP-MS analysis. The issue remain debated as matrix effects induced by sulfate on Si isotopes were not subsequently confirmed (Georg et al.,2006 ; Zambardi and Poitrasson, 2011; de Souza et al., 2012) and could potentially depend on plasma conditions of the MC-ICP-MS (Fietzke and Frische, 2015; Yu et al., 2020). A recent study provides constraints on matrix anion threshold concentrations and the extent of resulting biases, but the role of instrument type and different sample introduction systems (wet and dry plasma) has not been fully addressed (Oelze et al., 2016). However, as far as we are aware, there are no Si isotope data for reference materials with an organic-rich matrix. Because such a matrix is prone to induce $\delta^{30} \mathrm{Si}$ bias during MC-ICP-MS analysis, a lack of suitable reference materials is an issue of major importance for the analysis of soil or plant material. 
127 The aim of this paper is to provide the community with a set of easily available, well-

characterized reference materials containing organic material as part of the matrix for use as secondary reference materials in Si isotope analysis. We propose four soil reference materials (i.e., GBW-07401, GBW-07404, GBW-07407, TILL-1), representative of solid samples with a complex matrix with various Si-bearing phases (i.e., amorphous and/or crystalline silicate minerals, refractory minerals like iron oxy-hydroxides) and organic matter. In addition, the plant reference material ERM-CD281 (rye grass) was selected to represent the chemical composition of vegetation. It contains both organic matter and amorphous silica, which represents the form of Si generally accumulated in grass and then soils upon plant decay. This approach is an essential step in supporting $\delta^{30} \mathrm{Si}$ data comparison among and within laboratories over time.

\section{Materials and methods}

\subsection{Investigated materials}

This study investigates four soil reference materials GBW-07401, GBW-07404, GBW-07407, TILL-1 and one plant reference material ERM-CD281. The GBW soils "set", developed by the Institute of Geophysical and Geochemical Exploration (IGGE) of the Chinese Academy of Geological Sciences (CAGS) is not commercially available anymore. Because of this, an aliquot $(\sim g)$ of the batches analysed in this study can be obtained upon request to Isabelle Basile-Doelsch at CEREGE. Reference material TILL-1 is provided by the CCRMP (Canadian Certified Reference Materials Project) and ERM-CD281 is provided by the EC-JRC (European Commission - Joint Research Center), and both are readily available to the community. 
The reference material GBW-07401 is described as a dark brown podzolitic soil collected in a lead-zinc ore area, Heilongjiang, China; GBW-07404, as a limy-red soil obtained from Guangxi, China, and; GBW-07407, as a lateritic soil developed on basalt collected from Leizhou Peninsula, Guangdong, China (Wang et al., 2013). The reference material TILL-1 combines horizons B and C of a soil collected $25 \mathrm{~km}$ North-West of Lanark, Ontario, Canada (Lynch 1996). Among those soil reference materials, $\mathrm{SiO}_{2}$ content ranges from 32.67 to 62.60 $\% \mathrm{~m} / \mathrm{m}$, organic carbon $\left(\mathrm{C}_{\text {org }}\right)$ content varies from 0.62 to $1.80 \% \mathrm{~m} / \mathrm{m}$ and sulfur content varies from 5 to $310 \mathrm{mg} \mathrm{g}^{-1}$ (more details in Table 1). The plant reference material ERMCD281 is a rye grass, harvested in the United Kingdom in 1983, containing $0.13 \% \mathrm{~m} / \mathrm{m} \mathrm{Si}$ (Corg unknown) and $34 \mu^{-1} g^{-1} \mathrm{~S}$ (Table 1).

The reference materials were analysed for their $\delta^{29} \mathrm{Si}$ and $\delta^{30} \mathrm{Si}$ values in seven laboratories: University of Bristol Isotope Group, United Kingdom (BIG); Centre Européen de Recherche et d'Enseignement en Géosciences de l’Environnement, France (CEREGE); Géosciences Environnement Toulouse, France (GET); German Research Centre for Geosciences, Germany (GFZ); Institut Français de Recherche pour l'Exploitation de la Mer, France (IFREMER); St Andrews Isotope Geochemistry, University of St Andrews, United Kingdom (STAiG); and Water Quality Centre - Trent University, Canada (WQC). The reference materials, provided as homogeneous powders by suppliers, were split and spread among the different laboratories via mail. Laboratories each received an aliquot of about $1 \mathrm{~g}$ of GBW soil reference materials, $0.2 \mathrm{~g}$ of TILL-1 and $3 \mathrm{~g}$ of ERM-CD281. Each laboratory conducted sample preparation and $\mathrm{Si}$ isotope measurements using their own protocols as detailed in 
175 Table 2. Sample preparation protocols of all laboratories are adapted from Georg et al.

176 (2006) and hence are similar and consist of an alkaline fusion step followed by purification

177 on a cation exchange resin. In the following, we highlight the differences between the

178 sample preparation and measurement protocols. More details on the procedures used in

179 each participating laboratory are given in previous publications or in Supplementary

180 Materials. For BIG see Hatton et al., (2019); for CEREGE see Supplementary Materials; for

181 GET see Zambardi and Poitrasson (2011); for GFZ see Schuessler and von Blanckenburg

182 (2014) and Oelze et al. (2016); for IFREMER see Bayon et al., (2018); for STAiG see Savage

183 and Moynier (2013); for WQC see Georg et al. (2006).

One major difference between protocols relates to the use of calcination to

mineralize organic matter. CEREGE, GET and WQC calcinated the samples before fusion

while BIG, GFZ and IFREMER did not; STAiG processed replicates both with and without

calcination (see Supplementary Materials for detailed calcination procedures). All

laboratories performed $\mathrm{NaOH}$ fusion in silver crucibles except for IFREMER who used $\mathrm{NaOH}$ and $\mathrm{Na}_{2} \mathrm{O}_{2}$ in glassy carbon crucibles (Bayon et al., 2018). Finally, in order to purify the samples, all laboratories used column chromatography with cation exchange resin (either AG50W-X12 or AG50W-X8, see Table 2) based on the procedure developed by Georg et al. (2006). After alkali fusion, samples are normally taken up in a weakly acidic solution; many laboratories perform a measurement of solution Si concentration here (prior to Si purification), firstly to check for quantitative yield from the fusion step, and also to calculate the required amount of solution for column chemistry. 
the concentration measurements of $100 \pm 5 \%$ ) and ii) check the purity of the Si sample solutions, with a particular focus on confirming the lack of magnesium (Mg) within the sample in the laboratories using Mg doping. Purity was better than $95 \%$ for $\mathrm{Si}$, except for the plant ERM CD-281, where elevated levels of phosphorous and sulfur (mass ratios $\mathrm{PO}_{4} / \mathrm{Si}$ up to 5 and $\mathrm{SO}_{4} / \mathrm{Si}$ up to 6 ), respectively were still present. Complete removal of these anions was achieved neither by high temperature volatilisation during $\mathrm{NaOH}$ fusion at $750^{\circ} \mathrm{C}$ for 10 minutes (without prior calcination; GFZ) or calcination (CEREGE, no $\mathrm{SO}_{4}$ data), nor by the $\mathrm{Si}$ column chemistry. However, as discussed below, all impurities were still within the tolerance limits found to not cause any bias in Si isotope measurements using the MC-ICP-MS setup (instrument, sample introduction system, analyte matrix, Mg doping,...) used by the participating laboratories in this study.

Silicon isotope measurements were performed by MC-ICP-MS, either Neptune Plus MC-ICP-MS or Neptune MC-ICP-MS (both from Thermo Fisher Scientific, Germany) (Table 2). The analyses were performed in medium resolution $(m / \Delta m \sim 4500,5$ and $95 \%$ peak side definition, see Weyer and Schwieters, 2003; except for GET which utilised high resolution $(m / \Delta m \sim 7-10000))$ using between $0.5-3.6 \mu \mathrm{g}$ Si per analysis, which resulted in a $3-20 \mathrm{~V}$ ion beam on ${ }^{28} \mathrm{Si}$. Four laboratories carried out analyses in 'wet plasma mode', three in 'semi-dry plasma mode' using a desolvating nebulizer system (ESI Apex-HF, ESI Apex Q). The main advantage of a desolvation unit is to reduce polyatomic interferences from oxygen, nitrogen, carbon and hydrogen and to improve sensitivity. However, use of a desolvation unit increases matrix effects and results in a less stable signal. Subtraction of the blank signal (measured on the pure acid matrix solution) from all sample Si intensities was performed before subsequent data processing by all laboratories (BIG, GFZ, CEREGE, GET, STAiG). For all 
laboratories, full procedural blank Si intensities did not exceed $1 \%$ of the sample Si signal (Table 2).

All measurements were performed using the standard-sample-bracketing technique using NBS 28 (also named NIST SRM 8546) as the bracketing standard, except for IFREMER where an in-house standard previously calibrated against the NBS 28 was used. With the exception of STAiG and WQC laboratories, the purified Si solutions were also doped with Mg (Si:Mg ratio of 1 to 3, depending on the laboratories; Table 2) prior to mass spectrometric analysis for an additional online mass bias drift correction using an exponential mass bias equation (Cardinal et al., 2003; Engström et al., 2006; Zambardi and Poitrasson, 2011; Oelze et al., 2016), (Table 2). When Mg-doping was utilised, Mg isotopes were analysed along Si isotopes using dynamic mode (magnet jump alternating between $\mathrm{Si}$ and $\mathrm{Mg}$ isotopes) for each sample doped with $\mathrm{Mg}$. Magnesium doping is also useful to eliminate variations due to sample matrix effects or insufficiently stable laboratory temperature (Cardinal et al., 2003; Engström et al., 2006; Zambardi and Poitrasson, 2011; Oelze et al., 2016). Additionally, BIG samples were doped with $50 \mu \mathrm{l} 0.01 \mathrm{~mol}^{-1}$ sulfuric acid per ml of sample to reduce anionic matrix effects. Silicon isotope compositions are reported relative to the NBS 28 in the delta notation as $\delta^{30} \mathrm{Si}$ and $\delta^{29} \mathrm{Si}$ :

$$
\delta^{30,29} \mathrm{Si}(\%)=\left(\mathrm{R}_{\text {sample }} / \mathrm{R}_{\mathrm{NBS} 28}\right)-1
$$

where $\mathrm{R}$ is the ratio ${ }^{30} \mathrm{Si} /{ }^{28} \mathrm{Si}$ or ${ }^{29} \mathrm{Si} /{ }^{28} \mathrm{Si}$ in a sample, and $\mathrm{R}_{\mathrm{NBS} 28}$ the mean value for reference material NBS 28 calculated using the mean of the measured Si isotope ratio immediately measured before and after the unknown sample (i.e., standard-sample bracketing). The well-characterized Diatomite and/or BHVO-2 reference materials, for which large datasets are available in the literature, were measured routinely for quality control as unknown samples during the runs by all laboratories to check for accuracy and precision. 
These data are provided in Table 2, and are well in agreement with the published values compiled in Table S1 (i.e., mean $\delta^{30} \mathrm{Si}=-0.28 \pm 0.08 \%(U, k=2, \mathrm{~N}=61$ where $\mathrm{N}$ is the number of data published)).

At least three aliquots of each reference material used in this study were processed through the whole sample preparation, hereafter referred to as full procedure replicates, except for GET (N=1), WQC ( $N=1)$ and the additional uncalcinated aliquot of GBW-07401 and GBW-07407 processed by STAiG. Each full procedure replicate was then analysed between 3 and 14 times either on different days or on the same day but not consecutively depending on laboratories (see Table 2 for details). Each mass-spectrometric analysis comprises between 20 to 36 signal integrations of 4 to $8.4 \mathrm{~s}$, which is a total 80 to $210 \mathrm{~s}$ of Si signal acquisition per analysis. For each laboratory, replicate measurements carried out for each reference material full procedure replicate were averaged using the arithmetic mean and its associated 2 standard deviation (2SD; data are reported in Table S2).

\section{Results and discussion}

An essential measurement control is given by the three-isotope plot (Fig. 1). All data (from the reference materials full procedural replicates reported by each laboratory) fall on a straight line with a slope of about $\delta^{29} \mathrm{Si} \sim 0.5103 \times \delta^{30} \mathrm{Si}\left(r^{2}>99 \%\right)$. The linear correlation encompasses the theoretical slopes calculated for both equilibrium (0.5178) and kinetic (0.5092) mass-dependent fractionation processes (Engström et al., 2008), suggesting no major influence of isobaric interferences or matrix effects. In addition, the $\delta^{30} \mathrm{Si}$ and $\delta^{29} \mathrm{Si}$ 
values of the Diatomite and BHVO-2 reference materials measured by all laboratories agree well with compiled values (Reynolds et al., 2007; Savage et al., 2014; our compilation in Table S1). The absolute differences between published values and those produced by participating laboratories are smaller than $0.06 \%$ and $0.03 \%$ for $\delta^{30} \mathrm{Si}$ and $\delta^{29} \mathrm{Si}$, respectively, which are within the 2 SD reported by each laboratory (Table 2).

WQC reported $\delta^{30}$ Si calculated from measured $\delta^{29}$ Si assuming an equilibrium massdependent fractionation. Comparing WQC $\delta^{30} \mathrm{Si}$ results with values reported by other laboratories (Fig 2.) shows no notable difference between their calculated $\delta^{30} \mathrm{Si}$ and other laboratories measured $\delta^{30} \mathrm{Si}$, within their respective 2SD. This approach is therefore valid for the set of reference materials analysed in this study. However, this approach should be used with caution since it does not allow a data quality check for mass-dependent fractionation using the three-isotope plot (Fig 1.).

\subsection{Individual results of soil reference materials}

The $\delta^{30} \mathrm{Si}$ and $\delta^{29} \mathrm{Si}$ values obtained for each reference material (representing full procedural replicates) by participating laboratories are illustrated in Fig. 2 and provided in Table S2. The $\mathrm{Si}$ isotope composition of the five reference materials reported are indistinguishable within their 2SD, both between the full procedural replicates for a given laboratory, and also between laboratories. The $\delta^{30} \mathrm{Si}$ data range between $-0.30 \%<\delta^{30} \mathrm{Si}<-0.20 \%$ for GBW07401; - $0.90 \%$ \% $<\delta^{30} \mathrm{Si}<-0.67 \%$ for GBW-07404; $-2.05 \%<\delta^{30} \mathrm{Si}<-1.71 \%$ for GBW$07407 ;-0.21 \%<\delta^{30} \mathrm{Si}<-0.12 \%$ for TILL-1. This range of $\delta^{30} \mathrm{Si}$ values spans the typical $\delta^{30} \mathrm{Si}$ spectrum of soil materials ranging from $-2.7 \%$ to $+0.1 \%$ (Poitrasson, 2017). The most negative Si isotope compositions are measured in the reference materials with the lowest 
$\mathrm{SiO}_{2} / \mathrm{Al}_{2} \mathrm{O}_{3}$ mass ratio (GBW-07407), i.e., the soil which has undergone the most desilification

(Fig. 3). This is consistent with the general weathering trend, wherein the Si isotopic composition of secondary clay minerals formed during chemical weathering is lower than that of the primary silicate material (e.g., Opfergelt et al., 2010; Georg et al., 2009; Savage et al., 2013). Furthermore, the formation of more desilicified 1:1 clays is accompanied by a larger (negative) Si isotopic fractionation than the formation 2:1 clays (Georg et al., 2009; Opfegelt et al., 2012).

\subsection{Individual results of the plant reference material ERM-CD281}

Of the laboratories involved in this study, two did not analyse the ERM-CD281 rye grass reference material because they had not previously processed highly organic-rich material (i.e., plant matter) and methodological development was beyond the scope of this study. The $\delta^{30} \mathrm{Si}$ and $\delta^{29} \mathrm{Si}$ obtained for the plant reference material full procedure replicates by each laboratory are illustrated in Fig. 2 and provided in Table S2. The Si isotope compositions reported are indistinguishable within the 2SD both between the full procedural replicates for a given laboratory and between laboratories. The $\delta^{30} \mathrm{Si}$ data range between $-0.36 \% \circ<\delta^{30} \mathrm{Si}<$ $-0.26 \%$. In addition to the data acquired during this study, another published result for ERM-CD281 is available $\left(\delta^{30} \mathrm{Si}=-0.28 \pm 0.08 \%, 2 S D, n=3\right.$; Frick et al. 2020). These published analyses were performed at GFZ using the same protocol in the same laboratory as reported for GFZ in this study. The Si isotope values for ERM-CD281 fall within the large range of $\delta^{30} \mathrm{Si}$ values reported in the literature for biogenic silica in plants (-2.3 to $+6.1 \%$; Opfergelt and Delmelle, 2012). The range of Si isotope compositions is large because the $\delta^{30} \mathrm{Si}$ values of biogenic silica in plants depend on several factors such as soil parent material lithology, soil 
weathering degree and on complex isotope fractionation processes during Si uptake and deposition (Opfergelt et al., 2010).

\subsection{Influence of sulfur and DOC contents}

The importance of chemical purification in removing so-called matrix effects has already been described for several isotopes systems measured by MC-ICP-MS (see for example Galy et al., 2001, for Mg isotopes). For Si isotopes, significant effects induced by the presence of sulfur in rock samples were first reported by Van den Boorn et al. (2009), i.e., a Si isotope bias of up to $1.4 \%$ for a $\mathrm{SO}_{4} / \mathrm{Si}$ mass ratio higher than 0.02 . Subsequent studies have discussed the possibility of sulfur-induced bias on Si isotope measurements (Hughes et al., 2011; Zambardi and Poitrasson, 2011; Chemtob et al., 2015), and highlighted the potential for several parameters to influence the magnitude of the bias, notably in the dry plasma mode (Oelze et al., 2016). Thus, care must be taken when comparing studies and drawing conclusions is not that straightforward. In particular, comparing sulfur-induced bias between S-doped solutions and S-rich rocks is likely irrelevant. However, in this study, sulfur-induced matrix effects are less likely to be significant, because the $720^{\circ} \mathrm{C}$ fusion step of solid samples used by all laboratories will at least partially remove the sulfur, with full removal achieved by heating at $1350^{\circ} \mathrm{C}$ (Van den Boorn et al., 2009). Despite different analytical settings, this can partly explain the large decrease from +1.4 to $+0.3 \%$ o $\left(\mathrm{SO}_{4} / \mathrm{Si}\right.$ mass ratio $\left.\sim 0.3\right)$ between Van den Boorn et al. (2009) and Hughes et al. (2011) datasets as well as the absence of Si isotope bias measured on rock samples with $\mathrm{SO}_{4} / \mathrm{Si}$ mass ratios $\leq 0.14$ by Zambardi and Poitrasson (2011). To allow comparison between studies, it would be useful to provide $\mathrm{SO}_{4} / \mathrm{Si}$ ratios of the $\mathrm{Si}$ analyte solutions in addition to the usual initial sample $\mathrm{SO}_{4} / \mathrm{Si}$ ratios before processing. 
Restricting comparison to S-doped pure Si solutions (usually doped NBS 28), it appears that

342

343

344

345

346

347 several parameters may reduce the isotopic bias. Van den Boorn et al. (2009) noticed that $\mathrm{HCl} 0.1 \mathrm{~mol} \mathrm{I}^{-1}$ matrix reduces the bias by a factor about 1.5 compared to a $\mathrm{HNO}_{3}$ matrix. Also, Chemtob et al. (2015) noticed no significant bias due to sulfur for $\mathrm{SO}_{4} / \mathrm{Si}$ mass ratios $<1$ with a $0.002 \% \mathrm{HF}$ and $2 \% \mathrm{HNO}_{3}$ matrix despite very similar analytical parameters (i.e., the use of a Neptune, a CETAC desolvator and no Mg doping). It appears that the overall sample aliquot matrix plays a role in the magnitude of the S-induced bias in addition to subtle differences in instrumental set-up. Similarly, Georg et al. (2006) noticed no deviation from expected values for $\mathrm{SO}_{4} / \mathrm{Si}$ mass ratio up to 48 using a $\mathrm{Nu}$ instrument, a CETAC dessolvator in a $0.1 \mathrm{~mol} \mathrm{I}^{-1} \mathrm{HCl}$ matrix without Mg doping. Similarly, Zambardi and Poitrasson (2011) and Oelze et al (2016) investigated the effect with $\mathrm{Mg}$ doping. For $\mathrm{SO}_{4} / \mathrm{Si}$ ratios $<1$, the $\mathrm{Mg}$ doping had no effect on the magnitude of the S-induced bias (Zambardi and Poitrasson, 2011; Oelze et al., 2016). Moreover, Oelze et al (2016) found that the addition of Mg to the Si analyte solution resulted in higher tolerance to impurities during MC-ICP-MS analyses when an Apex desolvator without a membrane was used. Remaining anionic impurities $\left(\mathrm{PO}_{4}\right.$ ${ }^{3-}, \mathrm{SO}_{4}{ }^{2-}$, and $\mathrm{NO}_{3}{ }^{-}$) had no effect on the $\mathrm{Si}$ isotope mass bias (with accuracy within \pm 0.14 $\%$ ) if the mass ratio of those anions to Si is lower than 6 (Oelze et al., 2016). To overcome Sinduced bias, different techniques were suggested: removal of sulfur by heating the samples up to $1350^{\circ} \mathrm{C}$ (Van den Boorn et al., 2009) or doping both samples and bracketing standard with significant amounts of sulfuric acid to overwhelm any variation in the sample (Hughes et al., 2011).

In this study, no S-induced bias on Si isotopes measurements is expected for soil reference materials as $\mathrm{SO}_{4} / \mathrm{Si}$ mass ratios are below $0.01\left(\mathrm{SO}_{4} / \mathrm{Si}\right.$ mass ratio 0.003 for GBW-07401; 
reference material ERM-CD281 has a $\mathrm{SO}_{4} / \mathrm{Si}$ mass ratio about 7.8 that could potentially be problematic for Si isotopes measurements. This was verified in Si analyte solutions where elevated levels of phosphorous and sulfur (mass ratios $\mathrm{PO}_{4} / \mathrm{Si}$ up to 5 and $\mathrm{SO}_{4} / \mathrm{Si}$ up to 6), respectively, were still present after $\mathrm{NaOH}$ fusion (with or without prior calcination) and $\mathrm{Si}$ column purification. Complete removal of these anions was achieved neither by high temperature volatilisation nor by the Si column chemistry. However, all impurities were still within the limits required to avoid any bias for all different analytical configurations used by different laboratories (prior calcination or not, wet plasma or Apex desolvation, $\mathrm{Mg}$ doping or no $\mathrm{Mg}$ doping, $\mathrm{HCl}$ or $\mathrm{HNO}_{3}$ matrix). This is consistent with the study of Oelze et al., (2016) where no effect on the $\mathrm{Si}$ isotope mass bias is observed if the mass ratio of anions to $\mathrm{Si}$ is lower than 6 with an $\mathrm{Mg}$ correction (1 without an $\mathrm{Mg}$ correction). The Si isotope results of ERM CD-281 measured by laboratories using a regular spray chamber (wet plasma) agree well with those measured using an Apex sample introduction system. Similarly, the prior calcination of the sample has a limited efficiency (Fig. 2) and does not seem mandatory for $\mathrm{SO}_{4}$ removal in such samples. In all cases, the chemical preparation and analytical settings seem to be robust enough to avoid matrix effects caused by residual impurities in the sample during Si isotope measurements.

Hughes et al., (2011) also showed that measurable concentrations of dissolved organic carbon (DOC) in freshwater samples can affect their Si isotopic determination. Given the large spectrum of naturally occurring DOC forms, DOC-induced bias is suspected to be variable from one DOC form to another even before considering combined effects. This would make correcting for the presence of DOC in samples unworkable, due to the nearimpossibility of matching the matrix in the bracketing standards. Therefore, removal of 
organic matter during sample preparation seems to be the best option to ensure reliable analysis of organic carbon-rich samples.

The variability of the $\mathrm{SiO}_{2}$ and organic carbon contents of the soils reference materials used in this study allow for evaluation of the influence of varying matrix to analyte ratios with or without calcination steps. When comparing the results with or without organic matter mineralization, no notable offset is observed, regardless of the considered reference material (Fig. 2). In addition, STAiG laboratory calcinated their reference materials but also processed one aliquot each of GBW-07401 and GBW-07407 without calcination (Fig. 2). The results for both calcinated and uncalcinated aliquots of these two reference materials are identical within their 2SD (Fig. 2 and Table S2). In addition, at GFZ the removal of organic carbon by the $\mathrm{NaOH}$ fusion method $\left(750^{\circ} \mathrm{C}, 10\right.$ minutes $)$ - without prior calcination - was investigated. Effective organic carbon removal was found for all soil and plant samples processed at GFZ during this study using semi-quantitative ICP-OES analyses (carbon 193.027 $\mathrm{nm}$ emission line) by evaluation of $\mathrm{C}$ remaining in the post-fusion and purified Si solutions prior to Si isotope analyses. All solutions showed C-counts indistinguishable from pure acid used for dilution for the analyses, whereas significant $C$ intensities were recorded in sample aliquots that were not treated by alkali fusion and subsequent Si column purification. It thus seems that the presence of organic carbon has no impact on the accuracy or reproducibility of $\mathrm{Si}$ isotopes measurements if the high temperature alkaline fusion digestion is used (with or without prior calcination) as the remaining amount of organic matter is insufficient to induce Si isotopic bias. Several factors could explain this. The amount of organic matter in uncalcinated aliquots was insufficient to induce any bias. Indeed, $\mathrm{C}_{\text {org }} / \mathrm{Si}$ mass ratios of soil reference materials were below 0.1 while Hughes et al. (2011) observed a shift in freshwater samples from $\mathrm{DOC} / \mathrm{Si}>0.2$. However, the $\mathrm{Si}$ isotope measurement of the high $\mathrm{C}_{\text {org }} / \mathrm{Si}$ plant 
reference material ERM-CD281 analysed at IFREMER and GFZ - without prior calcination step - are not affected. In this case, it could be that the organic carbon in this sample is not refractory and is oxidised during the high-temperature fusion step as suggested by $C$ analyses at GFZ. Finally, it is also possible that the DOC form present in soils or plants does not induce bias, at least not on the Thermo Neptune-family of MC-ICP-MS instruments. More tests would be required to determine the critical DOC/Si ratio and if it is DOC-form sensitive.

3.5. Assigning $\delta^{30} \mathrm{Si}$ and $\delta^{29} \mathrm{Si}$ to the reference materials analysed in this study

Results from all seven laboratories are in excellent agreement for all reference materials (Fig.2), despite the use of different sample preparations (calcination versus no calcination; $\mathrm{NaOH}$ fusion versus $\mathrm{NaOH}$ and $\mathrm{Na}_{2} \mathrm{O}_{2}$ fusion) and different analytical settings (Mg doping vs no doping, wet plasma sample introduction vs semi-dry plasma; see Table 2). Therefore, the results reported by the laboratories for each reference material full procedural replicates (with the exception of the $\delta^{30}$ Si reported by WQC) were weighted and combined together to calculate averages and their associated combined uncertainties $(U, k=2)$. Final isotopic characterisation of the five reference materials analysed here are given in Table 3. Following the EURACHEM/CITAC Guide CG4, the combined uncertainties were calculated by error propagation, assuming independent variables, of the standard deviations obtained on full procedure replicates for each reference material, also including the standard deviation of the averages of full procedure replicates for each reference material. The combined uncertainties were multiplied by a coverage factor of $k=2$ to obtain the expanded uncertainties for each reference material. The uncertainties $(U, k=2)$ range from $0.04 \%$ to 
$0.12 \%$ for $\delta^{29} \mathrm{Si}$ and from $0.06 \%$ to $0.17 \%$ for the $\delta^{30} \mathrm{Si}$. The larger magnitude of $U$ for

$\delta^{30} \mathrm{Si}$ compared to those for $\delta^{29} \mathrm{Si}$ correspond with the lower natural abundance of ${ }^{30} \mathrm{Si}$ compared with ${ }^{29} \mathrm{Si}$ and the concomitant deterioration in counting statistics of the detectors. In addition, the uncertainties of these results (Table 3 ) are comparable with standard deviation obtained on multiple measurements of the reference materials Diatomite and BHVO-2 (Table 2) used by the laboratories to check for accuracy. Overall, the reference materials homogeneity is valid at the scale of the minimum sample mass used in this study, i.e., $>3 \mathrm{mg}$ for the soils reference materials, and at least $50 \mathrm{mg}$ for rye grass ERM CD281. The soils RM GBW-07401, GBW-07404, GBW-07407 and TILL-1 offer a wide range of $\delta^{29}$ Si and $\delta^{30} \mathrm{Si}$ values comparable to and therefore useful for future Si isotope environmental studies. The uncertainties obtained in this inter-laboratory comparison are more than one order of magnitude lower than the range of $\delta^{29} \mathrm{Si}$ and $\delta^{30} \mathrm{Si}$ measured in natural samples: -5.7 to +6.1 \%o (Opfergelt and Delmelle, 2012) and are therefore sufficient to allow the robust interpretation of small variations in the $\delta^{29} \mathrm{Si}$ and $\delta^{30} \mathrm{Si}$.

\section{Conclusion}

In this study, the $\delta^{29} \mathrm{Si}$ and $\delta^{30} \mathrm{Si}$ values of four soil and one plant reference materials were determined and compared between laboratories. Different sample preparation procedures and analytical settings provide consistent results for both $\delta^{29} \mathrm{Si}$ and $\delta^{30} \mathrm{Si}$ values for all reference materials. Therefore, all protocols used by the participating laboratories for Si isotope analysis provide comparable results. Also, no notable isotopic bias was observed between calcinated and uncalcinated reference materials with different $\mathrm{C}_{\text {org }} / \mathrm{Si}$ ratios. However, caution still stands for analyses of organic carbon-rich samples with a $\mathrm{C}_{\text {org }} / \mathrm{Si}$ ratio 
460 above the studied reference materials, where biases in $\delta^{30} \mathrm{Si}$ measurements could potentially

461 occur. This is particularly the case when sample preparation does not involve calcination,

462 leading to potential matrix effects during MC-ICP-MS analyses that could be DOC-form

463 dependent. The data for soil and plant reference materials from this study can be reliably

464 used by other laboratories for routine quality control of Si isotope ratio measurements

465 during environmental and geochemical studies. Moreover, the wide range of $\delta^{29} \mathrm{Si}$ and $\delta^{30} \mathrm{Si}$

466 covered by these soil reference materials provided here allows analysts to select the

467 reference materials that are best suited for their study. 
471 At CEREGE, this project was initiated by an EIL funding from the Société Française des Isotopes

472 Stables (SFIS) and also supported by the Agence Nationale pour la Recherche (ANR, France) through

473 the project EQUIPEX ASTER-CEREGE and the project BIOSiSOL (ANR-14-CE01-002). C.D. is funded by

474 the "Fonds National de la Recherche Scientifique" (Belgium). SF and the Si isotope measurements at

475 STAiG were supported by NERC grant NE/R002134/1 to PS; PS would also like to cite the support of a

476 Carnegie Trust Research Incentive Grant, which helped the setup of various isotope techniques in the

477 St Andrews Isotope Geochemistry (STAiG) laboratories. F. von Blanckenburg and the Helmholtz

478 Association are thanked for infrastructure support at GFZ. At the University of Bristol, C. D. Coath is

479 thanked for laboratory support and the European Research Council is acknowledged for funding (ICY-

480 LAB, grant agreement 678371). Hélène Mariot is thanked for her careful maintenance of the CEREGE

481 clean lab. Manuel Henry and Jérôme Chmeleff are thanked for maintaining the GET clean lab and

482 MC-ICP-MS facilities in good working order. J. Schlegel and J. Buhk are acknowledged for laboratory

483 support at GFZ. The authors declare that there is no conflict of interest.

484

485

Data availability Statement

486 The authors confirm that the data supporting the findings of this study are available within the article

487 and its Supplementary Materials. Detailed datasets are available from the corresponding author

488 upon reasonable request. 
Bibliography

Abraham K., Opfergelt S., Fripiat F., Cavagna A.J., de Jong J.T.M., Foley S.F., André L., Cardinal D. (2008) $\delta^{30} \mathrm{Si}$ and $\delta^{29} \mathrm{Si}$ determinations on USGS BHVO-1 and BHVO-2 reference materials with a new configuration on a Nu plasma multi-collector ICP-MS. Geostandards and Geoanalytical Research, 32,193 - 202.

Barnes, I. L., Moore, L. J., Machlan, L. A., Murphy, T. J., \& Shields, W. R. (1975) Absolute Isotopic Abundance Ratios and the Atomic Weight of a Reference Sample of Silicon. Journal of research of the National Bureau of Standards. Section A, Physics and chemistry, 79A(6), 727-735. https://doi.org/10.6028/jres.079A.029

Basile-Doelsch I. (2006) Si stable isotopes in the Earth's surface: A review. Journal of Geochemical Exploration, 88, 252- 256.

Bayon G., Delvigne C., Ponzevera E., Borges A.V., Darchambeau F., De Deckker P., Lambert T., Monin L., Toucanne S., André L. (2018) The silicon isotopic composition of fine-grained river sediments and its relation to climate and lithology. Geochimica et Cosmochimica Acta 229, $147-161$.

Berner R.A., Lasaga A.C., Garrels R.M. (1983) The carbonate-silicate geochemical cycle and its effect on atmospheric carbon dioxide over the past 100 million years. American Journal of Science, 283, 641-683.

Cardinal D., Alleman L.Y., de Jeong J., Ziegler K., André L. (2003) Isotopic composition of silicon measured by multicollector plasma source mass spectrometry in dry plasma mode. Journal Analytical Atomic Spectrometry, 18, 213-218.

Chemtob M., Rossman G. R., Young E. D., Ziegler K., Moynier F., Eiler J. M. and Hurowitz J. A. (2015) Silicon isotope systematics of acidic weathering of fresh basalts, Kilauea Volcano, Hawai'i. Geochimica et Cosmochimica Acta, 169, 63-81. 
Conley D.J. (2002) Terrestrial ecosystems and the global biogeochemical silica cycle. Global Biogeochemical Cycles, 16, 1121, doi:10.1029/2002 gb001894

de Souza G. F., Reynolds B. C., Rickli J., Frank M., Saito M. A., Gerringa L. J. A., and Bourdon B. (2012) Southern Ocean control of silicon stable isotope distribution in the deep Atlantic

Ocean. Global Biogeochemical Cycles, 26, GB2035, doi:10.1029/2011GB004141, 2012

De Bièvre P. and Taylor P. D. P. (1993) Table of the isotopic compositions of the elements.

International Journal of Mass Spectrometry and Ion Processes, 123, 149-166.

Engström E., Rodushkin I., Baxter D. C. and Öhlander B. (2006) Chromatographic Purification for the Determination of Dissolved Silicon Isotopic Compositions in Natural Waters by HighResolution Multicollector Inductively Coupled Plasma Mass Spectrometry. Analytical Chemistry, 78, 250-257.

Engström E., Rodushkin I., Öhlander B., Ingri J., Baxter D.C. (2008) Silicon isotopic composition of boreal forest vegetation in Northern Sweden. Chemical Geology, 257, 247256.

Engström E., Rodushkin I., Ingri J., Baxter D.C., Ecke F., Osterlund H., Ohlander B. (2010) Temporal isotopic variations of dissolved silicon in a pristine boreal river. Chemical Geology, $271,142-152$.

Fietzke J. and Frische M. (2015) Experimental evaluation of elemental behavior during LAICPMS: influences of plasma conditions and limits of plasma robustness. Journal of Analytical Atomic Spectrometry 31, 234-244.

Frick D. A., Remus R., Sommer M., Augustin J., and von Blanckenburg F. (2020) Silicon isotope fractionation and uptake dynamics of three crop plants: laboratory studies with transient silicon concentrations, Biogeosciences Discuss., https://doi.org/10.5194/bg-202066 , in review. 
Galy A., Belshaw N. S., Halicz L., O’Nions R. K. (2001) High-precision measurement of magnesium isotopes by multiplecollector inductively coupled plasma mass spectrometry. International Journal of Mass Spectrometry, 208, 89-98.

Georg R.B., Reynolds B.C., Frank M., Halliday A.N. (2006) New sample preparation techniques for the determination of Si isotopic compositions using MC-ICPMS. Chemical Geology, 235,95-104.

Georg R.B., West A.J., Basu A.R., Halliday A.N. (2009) Silicon fluxes and isotope composition of direct groundwater discharge into the Bay of Bengal and the effect on the global ocean silicon isotope budget. Earth Planetary Science Letters, 283, 67-74.

Grasse P., Brzezinski M. A., Cardinal D., de Souza G. F., Andersson P., Closset I., Cao Z., Dai M., Ehlert C., Estrade N., François R., Frank M., Jiang G., Jones J. L., Kooijman E., Liu Q., Lu D., Pahnke K., Ponzevera E., Schmitt M., Sun X., Sutton J. N., Thil F., Weis D., Wetzel F., Zhang A., Zhang J.and Zhang Z. (2017) GEOTRACES inter-calibration of the stable silicon isotope composition of dissolved silicic acid in seawater. Journal Analytical Atomic Spectrometry, 32, 562-578.

Hatton J. E., Hendry K. R., Hawkings J. R., Wadham J. L., Kohler T. J., Stibal M., Beaton A. D., Bagshaw E. A., and Telling J. (2019) Investigation of subglacial weathering under the Greenland Ice Sheet using silicon isotopes. Geochimica et Cosmochimica Acta, 247, 191-206. Hendry K., Leng M., Robinson L., Sloane H., Blusztjan J., Rickaby R., Georg R.B., Halliday, A. (2011) Silicon isotopes in Antarctic sponges: An interlaboratory comparison. Antarctic Science, $23,34-42$.

Hughes H.J., Delvigne C., Korntheuer M., de Jong J., André L., Cardinal D. (2011) Controlling the mass bias introduced by anionic and organic matrices in silicon isotopic measurements by MC-ICP-MS. Journal Analytical Atomic Spectrometry, 26, 1892-1896. 
Hughes H.J., Sondag F., Santos R.V., André L., Cardinal D. (2013) The riverine silicon isotope composition of the Amazon Basin. Geochimica et Cosmochimica Acta, 121, 637-651.

Jochum K. P., Nohl U., Herwig K., Lammel E., Stoll B., and Hofmann A. W. (2005) GeoReM: A New Geochemical Database for Reference Materials and Isotopic Standards. Geostandards and Geoanalytical Research, 29, 333-338.

Lynch J. (1996). Provisional elemental values for four new geochemical soil and till reference materials, TILL-1, TILL-2, TILL-3 and TILL-4. Geostandards Newsletter, 20, 277-287.

Mangalaa K.R., Cardinal D., Brajard J., Rao D.B., Sarma N.S., Djouraev I., Chiranjeevulu G., Murty K. N., Sarma V.V.S.S. (2017). Silicon cycle in Indian estuaries and its control by biogeochemical and anthropogenic processes. Continental Shelf Research, 148, 64-88. Nelson D. M., P. Tréguer, M. A. Brzezinski, A. Leynaert, and B. Quéguiner (1995) Production and dissolution of biogenic silica in the ocean: Revised global estimates, comparison with regional data and relationship to biogenic sedimentation. Global Biogeochemical Cycles, 9, $359-372$.

Oelze M., Schuessler J.A., von Blanckenburg F. (2016) Mass bias stabilization by Mg doping for Si stable isotope analysis by MC-ICP-MS. Journal of Analytical Atomic Spectrometry, 31, 2094-2100.

Opfergelt S., Cardinal D., André L., Delvigne C., Bremond L., Delvaux B. (2010) Variations of $\delta^{30} \mathrm{Si}$ and $\mathrm{Ge} / \mathrm{Si}$ with weathering and biogenic input in tropical basaltic ash soils under monoculture. Geochimica et Cosmochimica Acta, 74, 225-240.

Opfergelt S. and Delmelle P. (2012) Silicon isotopes and continental weathering processes: Assessing controls on Si transfer to the ocean. Comptes Rendus Geoscience, 344, 723-738. Poitrasson F. (2017) Silicon Isotope Geochemistry. Reviews in Mineralogy and Geochemistry, $82,289-344$. 
585

586

587

Ragueneau O., Schultes S., Bidle K., Claquin P., and Moriceau B. (2006) Si and C interactions in the world ocean: Importance of ecological processes and implications for the role of diatoms in the biological pump. Global Biogeochemical Cycles, 20, GB4S02.

Reynolds B.C., Aggarwal J., André L., Baxter D., Beucher C., Brzezinski M.A., Engström E., Georg R.B., Land M., Leng M.J., Opfergelt S., Rodushkin I., Sloane H.S., van den Boorn S.H.J.M., Vroon P.Z., Cardinal D. (2007) An inter-laboratory comparison of Si isotope reference materials. Journal of Analytical Atomic Spectrometry, 22, 561-568. Savage P.S., Georg R.B., Williams H.M., Halliday A.N. (2013) The silicon isotope composition of the upper continental crust. Geochimica et Cosmochimica Acta, 109, 384-399.

Savage P.S., Armytage R.M.G., Georg R. B., Halliday A. N. (2014) High temperature silicon isotope geochemistry, Lithos, 190, 500-519.

Savage P.S., Moynier F. (2013) Silicon isotopic variation in enstatite meteorites: Clues to their origin and Earth forming material. Earth Planetary Science Letters, 361, 487-496.

Schuessler J.A. and von Blanckenburg F. (2014) Testing the limits of micro-scale analyses of Si stable isotopes by femtosecond laser ablation multicollector inductively coupled plasma mass spectrometry with application to rock weathering. Spectrochimica Acta Part B: Atomic Spectroscopy, 98, 1-18.

Street-Perrott F. A. and Barker P.A. (2008) Biogenic silica: a neglected component of the coupled global continental biogeochemical cycles of carbon and silicon. Earth Surface Processes and Landforms, 33, 1436-1457.

Struyf E. and Conley D.J. (2012) Emerging understanding of the ecosystem silica filter. Biogeochemistry, 107, 9-18. 
van den Boorn S. H. J.M., Vroon P. Z. and Bergen M. J. (2009) Sulfur-induced offsets in MCICP-MS silicon-isotope measurements. Journal of Analytical Atomic Spectrometry,24, 11116091114.

610 Vandevenne F. I., Delvaux C., Hughes H. J., André L., Ronchi B., Clymans W., Barão L., Govers 611 G., Meire P., Struyf E., and Cornelis J. T. (2015). Landscape cultivation alters $\delta^{30}$ Si signature in

612

613

614

615

616

617 terrestrial ecosystems. Scientific reports, 5, 7732.

Weyer S. and Schwieters J. (2003). High precision Fe isotope measurements with mass resolution MC-ICP-MS. International Journal of Mass Spectrometry, 226, 355-368.

Yu Y., Siebert C., Fietzke J., Goepfert T., Hathorne E., Cao Z., and Frank M. (2020). The impact of MC-ICP-MS plasma conditions on the accuracy and precision of stable isotope measurements evaluated for barium isotopes. Chemical Geology, 549, 110697.

Zambardi T. and Poitrasson F. (2011) Precise Determination of Silicon Isotopes in Silicate Rock Reference Materials by MC-ICP-MS. Geostandards and Geoanalytical Research, 35, 8999. 